\title{
QTL and candidate gene mapping for polyphenolic composition in apple fruit
}

\author{
David Chagné ${ }^{1 * \dagger}$, Célia Krieger ${ }^{1,2+}$, Maysoon Rassam³ ${ }^{3}$ Mike Sullivan ${ }^{3}$, Jenny Fraser ${ }^{4}$, Christelle André ${ }^{3}$, \\ Massimo Pindo ${ }^{5}$, Michela Troggio ${ }^{5}$, Susan E Gardiner ${ }^{1}$, Rebecca A Henry ${ }^{3}$, Andrew C Allan ${ }^{3,6}$, Tony K McGhie ${ }^{1}$ and \\ William A Laing ${ }^{3}$
}

\begin{abstract}
Background: The polyphenolic products of the phenylpropanoid pathway, including proanthocyanidins, anthocyanins and flavonols, possess antioxidant properties that may provide health benefits. To investigate the genetic architecture of control of their biosynthesis in apple fruit, various polyphenolic compounds were quantified in progeny from a 'Royal Gala' × 'Braeburn' apple population segregating for antioxidant content, using ultra high performance liquid chromatography of extracts derived from fruit cortex and skin.

Results: Construction of genetic maps for 'Royal Gala' and 'Braeburn' enabled detection of 79 quantitative trait loci (QTL) for content of 17 fruit polyphenolic compounds. Seven QTL clusters were stable across two years of harvest and included QTLs for content of flavanols, flavonols, anthocyanins and hydroxycinnamic acids. Alignment of the parental genetic maps with the apple whole genome sequence in silico enabled screening for co-segregation with the QTLs of a range of candidate genes coding for enzymes in the polyphenolic biosynthetic pathway. This colocation was confirmed by genetic mapping of markers derived from the gene sequences. Leucoanthocyanidin reductase (LAR1) co-located with a QTL cluster for the fruit flavanols catechin, epicatechin, procyanidin dimer and five unknown procyanidin oligomers identified near the top of linkage group (LG) 16, while hydroxy cinnamate/ quinate transferase (HCT/HQT) co-located with a QTL for chlorogenic acid concentration mapping near the bottom of LG 17 .
\end{abstract}

Conclusion: We conclude that $L A R 1$ and $H C T / H Q T$ are likely to influence the concentration of these compounds in apple fruit and provide useful allele-specific markers for marker assisted selection of trees bearing fruit with healthy attributes.

Keywords: Malus x domestica, polyphenolic, QTL mapping, candidate gene, flavonoid, flavanol, anthocyanin, tannin, metabolomics

\section{Background}

Nutritionists have recommended an increased consumption of fruits and vegetables, as sources of dietary compounds such as fibre, micronutrients and antioxidant compounds that are beneficial to human health [1]. Apple (Malus $\mathrm{x}$ domestica Borkh.) is considered to be part of such a healthy diet, being very low in total calories and a good source of dietary fibre $(2 \mathrm{~g} / 100 \mathrm{~g}$ fresh

\footnotetext{
* Correspondence: David.Chagne@plantandfood.co.nz

+ Contributed equally

${ }^{1}$ The New Zealand Institute for Plant \& Food Research Limited (Plant \& Food Research), Palmerston North Research Centre, Palmerston North 4442, New Zealand

Full list of author information is available at the end of the article
}

fruit) $[2,3]$. While apples are lower in vitamin $C$ than other fruits $(5-25 \mathrm{mg} / 100 \mathrm{~g}$ depending on the cultivar [4]), they have very high concentrations of other antioxidant phytochemicals, especially polyphenolic compounds such as quercetin, epicatechin, and procyanidin polymers $[2,5,6]$.

Numerous epidemiological studies have suggested that polyphenolic compounds are involved in the prevention of degenerative diseases such as epithelial (but not hormone-related) cancers and cardiovascular diseases, type2 diabetes, thrombotic stroke, obesity, neurodegenerative diseases associated with aging and infections [7]. Although polyphenolic compounds have long been
C Biomed Central

() 2012 Chagné et al; licensee BioMed Central Ltd. This is an Open Access article distributed under the terms of the Creative Commons Attribution License (http://creativecommons.org/licenses/by/2.0), which permits unrestricted use, distribution, and reproduction in any medium, provided the original work is properly cited. 
studied for their antioxidant properties, which are now well characterized in vitro, recent studies have stressed that the mechanisms of biological actions of polyphenols extend beyond their antioxidant properties [8]. It is now believed that polyphenols may exert their beneficial action through the modulation of gene expression and the activity of a wide range of enzymes and cell receptors $[9,10]$. However, the health effects of dietary polyphenols depend on the amounts consumed and on their bioavailability. Previous studies suggest that the bioavailability of polyphenols is related to their chemical structure [11]. For instance, the nature of the sugar conjugate and the phenolic aglycone are both important for anthocyanin absorption and excretion.

Several thousand compounds having a polyphenolic structure have been identified in higher plants $[12,13]$. These compounds are secondary metabolites involved in defence against aggression by pathogens or ultraviolet radiation. The most important groups of polyphenols in plants are the flavonoids, phenolic acids, lignans and stilbenes. The flavonoid group can be subdivided into seven subgroups: flavonols, flavones, isoflavones, flavanols, flavanones, anthocyanins and dihydrochalcones of which flavonols, flavanols, anthocyanins and dihydrochalcones are found in apple [14]. The flavonols' main representatives, quercetin and kaempferol, are present in glycosylated forms and the associated sugar moiety is often glucose or rhamnose. Flavanols are not glycosylated, and exist in both the monomer form (catechins) and the polymer form (procyanidins or condensed tannins). Catechin and epicatechin are the main flavanols in fruits and are the building blocks for dimeric, oligomeric and polymeric procyanidins. Anthocyanins are pigments dissolved in the vacuolar sap of usually the epidermal tissues of fruits and exist in a range of chemical forms that are blue, red, purple, pink or colourless according to $\mathrm{pH}$. They are highly unstable as aglycones and in plants are found in glycosylated forms that are stable under light, $\mathrm{pH}$ and oxidizing conditions. Cyanidin and pelargonidin are the most common anthocyanins in foods. Finally, dihydrochalcones are a family of the bicyclic flavonoids, defined by the presence of two benzenoid rings joined by a three-carbon bridge. Phloridzin, which belongs to the dihydrochalcone family, is present in apple fruits [14].

Two classes of phenolic acids can be distinguished: derivatives of benzoic acid, and derivatives of cinnamic acid. These acids are found in plants both free and esterified with sugars or other organic acids [15]. Hydroxycinnamic acids are more common than hydroxybenzoic acids, with the main compounds of the hydroxycinnamic acid class being $p$-coumaric, caffeic, and chlorogenic acids. Hydroxybenzoic and hydroxycinnamic acids are also components of complex structures such as hydrolysable tannins (gallotannins and ellagitannins) and lignins, respectively.

Polyphenolic content and identity can vary according to location within the fruit (e.g. skin v. cortex), stage of fruit maturity, location of the fruit within the plant structure and time since harvest. Fruit polyphenolic concentration varies among apple cultivars [2], making this character a potential breeding target. However, current apple breeding programmes emphasize appearance (skin colour, pattern and amount of fruit covered with colour, size and shape of the fruit), eating quality (flavour and texture), and storage ability. Breeding for pest and disease resistances is the second major objective [16]. We are not aware of a breeding programme for apple that includes phytochemical properties and antioxidant content, despite the importance of healthy nutraceutical compounds from apple and other fruit. Consequently genetic mapping studies have focused on fruit quality and disease resistance and only a few have dealt with apple phytochemical content. Quantitative trait loci (QTL) for vitamin C have been identified following analysis of a 'Telamon' $\times$ 'Braeburn' segregating population [4] and a major locus for anthocyanin content in apple flesh has been mapped to linkage group (LG) 9 [17]. Expression of this locus has been characterised as being controlled by MYB10 $[18,19]$.

This study analyses the genetic control of fruit polyphenolic concentrations using a segregating $F_{1}$ population obtained from a cross between apple cultivars 'Royal Gala' and 'Braeburn', together with information from the apple whole genome sequence (Velasco et al. 2010). Once quantitative trait loci (QTL) were defined, candidate genes coding for enzymes involved in the synthesis of polyphenolic compounds were identified using genome sequencing and confirmed by genetic mapping. On the basis of our results, we suggest that a mutation in LAR1 is the probable cause of the variation in the concentration of flavanols in the fruit cortex and skin and that a similar change in $H Q T / H C T$ possibly causes variation in chlorogenic acid.

\section{Results}

\section{Analysis of apple polyphenolics by UHPLC in the 'Royal} Gala' $\times$ 'Braeburn' segregating population

Fruit from a 'Royal Gala' × 'Braeburn' segregating population were analysed using ultra high performance liquid chromatography (UHPLC) in 2008 and 2010 (Figure 1). Twenty-three compounds with variable concentrations were quantified in the apple fruit cortex and skin samples in 2010 and 16 compounds in 2008 (Table 1). The concentration of each compound varied depending on the compound and tissue. The minimum concentration observed for all 23 compounds was below the detection limit of the instrument. 


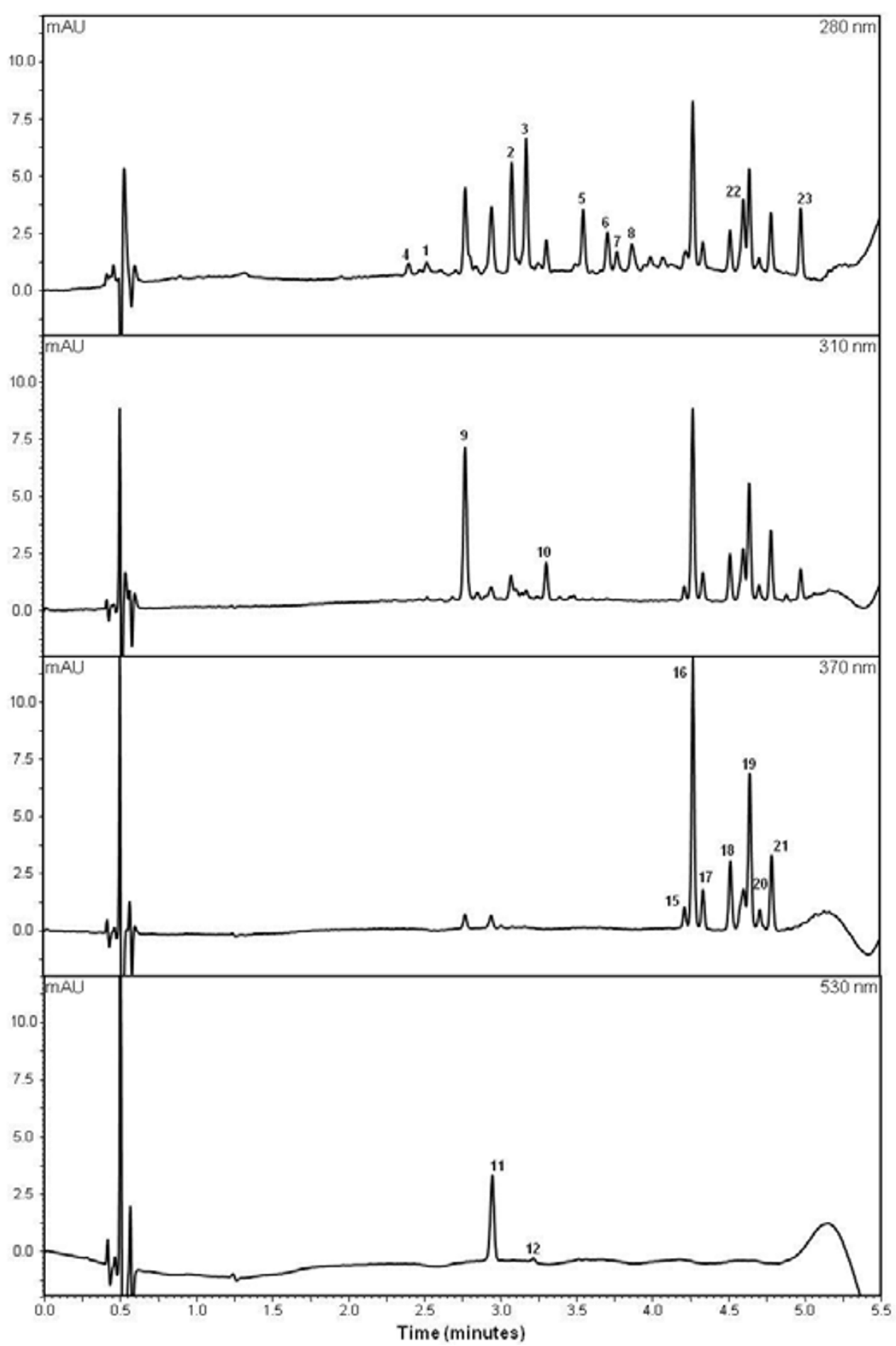

Figure $1 \mathrm{~A}$ representative set of chromatogram traces $(\mathbf{2 8 0}, \mathbf{3 1 0}, \mathbf{3 7 0}$, and $\mathbf{5 3 0} \mathrm{nm})$ typical of apple skin. This example shows the chromatograms of skin from 'Royal Gala' fruit sampled in 2010. Chromatographic peaks are labelled according to the compound number provided in Table 1. Sample preparation and UHPLC parameters are described, in detail, in the 'Methods' section. 
Table 1 Range in concentration of 23 polyphenolic compounds isolated from apple fruit skin and cortex of progeny from the 'Royal Gala' × 'Braeburn' segregating population, across two years.

\begin{tabular}{|c|c|c|c|c|c|c|c|c|c|c|c|c|c|c|c|c|c|}
\hline \multirow{3}{*}{$\#$} & \multirow{3}{*}{ Compound } & \multicolumn{6}{|c|}{2008} & \multicolumn{10}{|c|}{2010} \\
\hline & & \multicolumn{3}{|c|}{ Skin } & \multicolumn{3}{|c|}{ Cortex } & \multicolumn{5}{|c|}{ Skin } & \multicolumn{5}{|c|}{ Cortex } \\
\hline & & Mean & Max. & Min. & Mean & Max. & Min. & Mean & Max. & Min. & $B B^{A}$ & $R G^{A}$ & Mean & Max. & Min. & $B B^{A}$ & $R G^{A}$ \\
\hline 1 & (+)-catechin & 19.2 & 131.7 & 0.0 & 13.9 & 135.2 & 0.0 & 14.5 & 172.0 & 1.0 & 8.5 & 15.4 & 15.4 & 241.5 & 2.0 & 5.0 & 11.5 \\
\hline 2 & procyanidin B2 & 157.2 & 510.5 & 0.0 & 55.0 & 233.7 & 0.0 & 126.7 & 475.9 & 4.8 & 155.7 & 178.8 & 31.5 & 299.2 & 2.2 & 48.4 & 44.9 \\
\hline 3 & (-)-epicatechin & 201.6 & 709.3 & 0.0 & 57.5 & 277.6 & 0.0 & 134.9 & 533.9 & 5.8 & 154.4 & 209.0 & 47.7 & 316.6 & 2.4 & 44.1 & 53.8 \\
\hline 4 & procyanidin unk1 & & & & & & & 15.2 & 113.7 & 0.5 & 8.9 & 22.1 & 16.7 & 140.6 & 1.3 & 11.8 & 15.5 \\
\hline 5 & procyanidin unk2 & & & & & & & 76.1 & 275.2 & 2.5 & 106.0 & 105.0 & 28.4 & 178.5 & 1.6 & 25.7 & 29.1 \\
\hline 6 & procyanidin unk3 & & & & & & & 51.6 & 169.7 & 1.7 & 72.2 & 60.3 & 16.1 & 103.0 & 1.3 & 12.8 & 14.5 \\
\hline 7 & procyanidin unk4 & & & & & & & 26.3 & 89.2 & 0.8 & 35.7 & 28.8 & 11.5 & 59.8 & 1.6 & 8.2 & 7.9 \\
\hline 8 & procyanidin unk5 & & & & & & & 43.7 & 142.5 & 2.0 & 63.8 & 54.5 & 15.6 & 85.2 & 1.3 & 12.6 & 14.5 \\
\hline 9 & 3-O-caffeoylquinic acid & 96.4 & 465.1 & 0.0 & 152.6 & 601.8 & 0.0 & 121.2 & 724.2 & 8.5 & 11.9 & 94.0 & 177.0 & 985.9 & 48.6 & 99.6 & 133.5 \\
\hline 10 & p-coumaroylquinic acid & 28.1 & 90.8 & 0.0 & 56.4 & 219.9 & 0.0 & 32.1 & 217.4 & 2.3 & 22.2 & 18.5 & 56.0 & 343.4 & 3.0 & 41.0 & 38.3 \\
\hline 11 & cyanidin-3-O-galactoside & 50.7 & 324.3 & 0.0 & 0.0 & 0.0 & 0.0 & 50.0 & 242.6 & 1.2 & 105.4 & 45.0 & 0.0 & 0.0 & 0.0 & n.d. & n.d. \\
\hline 12 & cyanidin-3-O-arabinoside & 2.8 & 23.3 & 0.0 & 0.0 & 1.1 & 0.0 & 9.7 & 43.2 & 1.1 & 6.2 & 2.0 & 0.0 & 0.0 & 0.0 & n.d. & n.d. \\
\hline 13 & cyanidin-unk1 & & & & & & & 18.2 & 415.2 & 0.7 & 4.8 & n.d. & 0.0 & 0.0 & 0.0 & n.d. & n.d. \\
\hline 14 & cyanidin-unk2 & & & & & & & 11.5 & 25.4 & 4.8 & n.d. & n.d. & 0.0 & 0.0 & 0.0 & n.d. & n.d. \\
\hline 15 & quercetin-3-O-rutinoside & 61.1 & 228.5 & 0.0 & 0.0 & 0.0 & 0.0 & 38.5 & 217.6 & 3.7 & 14.4 & 17.0 & 0.0 & 0.0 & 0.0 & n.d. & n.d. \\
\hline 16 & quercetin-3-O-galactoside & 611.9 & 1518.2 & 0.0 & 0.4 & 6.5 & 0.0 & 389.5 & 1510.4 & 16.2 & 222.9 & 221.4 & 0.0 & 0.0 & 0.0 & n.d. & n.d. \\
\hline 17 & quercetin-3-O-glucoside & 102.1 & 316.6 & 0.0 & 0.1 & 2.3 & 0.0 & 66.3 & 309.1 & 14.2 & 25.0 & 32.5 & 0.0 & 0.0 & 0.0 & n.d. & n.d. \\
\hline 18 & quercetin-3-O-xyloside & 180.9 & 711.5 & 0.0 & 0.1 & 3.5 & 0.0 & 81.6 & 222.8 & 29.1 & 57.1 & 57.7 & 0.0 & 0.0 & 0.0 & n.d. & n.d. \\
\hline 19 & quercetin-3-O-pyranoarabinoside & 201.5 & 481.0 & 0.0 & 0.1 & 3.1 & 0.0 & 156.9 & 492.8 & 3.8 & 85.9 & 129.4 & 0.0 & 0.0 & 0.0 & n.d. & n.d. \\
\hline 20 & quercetin-3-O-furanoarabinoside & 23.2 & 71.8 & 0.0 & 0.0 & 3.4 & 0.0 & 20.4 & 60.3 & 4.4 & 10.7 & 20.6 & 0.0 & 0.0 & 0.0 & n.d. & n.d. \\
\hline 21 & quercetin-3-O-rhamnoside & 98.8 & 303.8 & 0.0 & 0.6 & 4.8 & 0.0 & 80.0 & 300.1 & 24.9 & 53.3 & 61.4 & 0.0 & 0.0 & 0.0 & n.d. & n.d. \\
\hline 22 & $\begin{array}{l}\text { phloretin-2'-O-(2"-O-xylosyl) } \\
\text { glucoside }\end{array}$ & 44.7 & 143.2 & 0.0 & 9.1 & 30.6 & 0.0 & 53.9 & 159.3 & 16.7 & 43.3 & 50.7 & 8.1 & 42.5 & 0.7 & 8.2 & 8.9 \\
\hline 23 & phloretin-2'-O-glucoside & 44.1 & 167.3 & 0.0 & 8.9 & 23.1 & 0.0 & 39.3 & 112.2 & 9.1 & 39.7 & 38.0 & 9.2 & 67.2 & 1.1 & 11.0 & 6.7 \\
\hline
\end{tabular}

The concentrations are expressed in $\mu \mathrm{g} / \mathrm{g}$ of fresh weight. Min.: Minimum; Max.: Maximum; RG: 'Royal Gala'; BB: 'Braeburn'.

\section{Flavonols}

Quercetin glycosides were the only flavonols detected in the apples analysed. Seven main quercetin glycosides were identified: quercetin 3-O-rutinoside, quercetin 3-Ogalactoside, quercetin 3-O-glucoside, quercetin 3-Oxyloside, quercetin 3-O-arabinopyranoside, quercetin 3$\mathrm{O}$-arabinofuranoside, and quercetin 3-O-rhamnoside. The most concentrated flavonol was quercetin 3-Ogalactoside. Quercetin aglycone was detected for two individuals only, one in the fruit skin and another in the cortex. Flavonols predominated in the fruit skin; however, these were virtually absent or not detected in the cortex (Table 1). The correlations between fruit harvested in 2008 and 2010 ranged from $r^{2}=0.14$ to $r^{2}=$ 0.38 and there was no correlation for quercetin 3-Oxyloside between years. Skin flavonols were highly correlated among themselves and showed medium to high correlations with other polyphenolic compounds present in the skin, such as anthocyanins, flavanols and dihydrochalcones (Additional File 1; Table S1). All flavonol compounds exhibited a skewed phenotypic distribution in the 'Royal Gala' × 'Braeburn' segregating population in both 2008 and 2010 (Additional File 2; Figure S1).

\section{Flavanols}

Eight flavanol compounds represented the second major class of compounds in both skin and cortex. Three were identified as catechin, procyanidin B2 and epicatechin. Five compounds matched procyanidin spectra and were deemed unknown procyanidin oligomers. Epicatechin was the compound with highest concentrations in both skin and cortex, followed by procyanidin B2. The correlations for flavanol concentration between years were medium $\left(r^{2}=0.32\right.$ for skin catechin) to high $\left(r^{2}=0.69\right.$ for cortex catechin). Flavanols were highly correlated among themselves within the cortex and skin, and between cortex and skin, and with flavonols in the skin. All flavanols showed a skewed distribution in the 'Royal Gala' × 'Braeburn' segregating population, except for cortex procyanidin B2 and the unknown procyanidins 2 and 3, which exhibited bimodal distributions.

\section{Anthocyanins}

Four cyanidin glycosides were identified: cyanidin 3-Ogalactoside, cyanidin 3-O-arabinoside, and two unknown cyanidins. Anthocyanins predominated in the fruit skin and were virtually absent from the cortex of fruit from the 'Royal Gala' x 'Braeburn' population. The year to 
year correlations for cyanidin 3-O-arabinoside and cyanidin 3-O-galactoside were medium high $\left(r^{2}=0.27\right.$ and $r^{2}=0.54$, respectively). Cyanidin 3-O-galactoside was intermediately correlated with flavanol $\left(r^{2}=0.45\right.$ with quercetin 3-O-galactoside) and flavonol compounds in the skin $\left(r^{2}=0.26\right.$ with epicatechin). All anthocyanin compounds exhibited a skewed distribution in the segregating population.

\section{Hydroxycinnamic acids}

Chlorogenic acid (3-O-caffeoyl quinic acid) and $p$-coumaroyl quinic acid were found in both skin and cortex of the apples. Although the total hydroxycinnamic acids were only a small proportion of the total polyphenolic profile of the skin, they represented the major group in the fruit cortex, with chlorogenic acid accounting for nearly $40 \%$ of all polyphenolics detected in the cortex. The correlation between years was high for both compounds except for skin $p$-coumaroyl quinic acid $\left(r^{2}=\right.$ 0.32). Both chlorogenic acid and $p$-coumaroyl quinic acid showed skewed distributions in both skin and cortex in the 'Royal Gala' $\times$ 'Braeburn' segregating population.

\section{Dihydrochalcones}

Phloridzin and phloridzin-xyloside were the only dihydrochalcones found in both skin and cortex of apple. The year to year correlation for both compounds was low to medium $\left(r^{2}=0.08\right.$ to $\left.r^{2}=0.41\right)$. Skin phloridzin and phloridzin-xyloside was correlated with both skin flavanol and flavonol compounds. All skin and cortex dihydrochalcones exhibited a skewed distribution in the segregating population.

\section{Genetic map construction and QTL analysis}

A total of 951 single nucleotide polymorphism (SNP) markers originally developed from 'Golden Delicious' to genetically anchor the 'Golden Delicious' apple genome sequence [20] were genotyped in the 590 individuals of the 'Royal Gala' $\times$ 'Braeburn' segregating population using 20 SNPlex $^{\mathrm{TM}}$ assays. Of these SNP markers, 511 (53.7\%) were polymorphic, while 158 (16.6\%) failed and $282(29.6 \%)$ were monomorphic. Genetic maps anchored to the apple genome sequence were constructed for both parents using the subset of 170 individuals that was phenotyped for polyphenolic compounds. A subset of 118 SNP markers was used to construct a 'Braeburn' genetic map with as even a marker distribution as possible and favouring backcross type markers $(a b \times a a)$ above less informative intercross markers $(a b \times a b)$. This map spanned a cumulative distance of $1,004.8 \mathrm{cM}$, covered all 17 LGs, had an average of one marker every $8.5 \mathrm{cM}$ and its largest gap was $32.5 \mathrm{cM}$ (Additional File 3; figure S2). One linkage group (LG 7) spanned only $4.1 \mathrm{cM}$ and had only three markers. Ninety-six markers were of the backcross type $(a b \times a a)$ and 22 were intercross type $(a b \times a b)$. A subset of 132 SNP markers was used to build the 'Royal Gala' genetic map, using similar distribution and segregation type criteria as for the 'Braeburn' map; 129 of these were of the backcross type and 3 were the less informative intercross type. The cumulative genetic size for the 'Royal Gala' genetic map was $863.9 \mathrm{cM}$, covering all 17 LGs, with an average of one marker every $6.7 \mathrm{cM}$ and a largest gap of 31.3 cM.

Seventy-nine QTLs for 17 compounds were detected over 9 LGs using multiple QTL (MQM) analysis (Table $2 \mathrm{a}$ ), with explained genotypic variation ranging from $5 \%$ to $71.8 \%$. Four QTLs for Procyanidin B2 and two unknown procyanidin oligomers were detected using the Kruskal-Wallis test (Table 2b). Forty-one and 38 QTLs were detected on the 'Royal Gala' and 'Braeburn' maps, respectively. The largest cluster of QTLs was located at the top of LG 16, where 42 QTLs were detected for flavanol compounds within the same region on both parental maps. Seven clusters were found where QTLs were stable between years and for classes of compounds (Figure 2), including: quercetin 3-O-rutinoside in fruit skin for 'Royal Gala' on LG 17; cyanidin 3-O-galactoside and cyanidin 3-O-arabinoside in fruit skin for both parents on LG 9; all eight measured flavanols in fruit skin and cortex for both parents on LG 16; chlorogenic acid in fruit skin and cortex for 'Royal Gala' on LG 17; $p$ coumaroyl quinic acid in fruit cortex for 'Braeburn' on LG 15; $p$-coumaroyl quinic acid in fruit skin and cortex for 'Royal Gala' on LG 1; $p$-coumaroyl quinic acid in fruit skin and cortex for both parents on LG 14. Other QTLs were detected on LGs 1, 6, 7, 9, 13 and 17 for a range of compounds in individual years, but were not found across years.

\section{Candidate gene co-location with QTLs}

Candidate genes predicted on the basis of involvement in the polyphenolic biosynthetic pathway (Additional File 4; Figure S3) were located bioinformatically on the 'Golden Delicious' whole genome sequence assembly using BLASTN analysis (Table 3).

Three candidate genes co-located bioinformatically with QTL clusters related to corresponding compound concentrations. A putative hydroxy cinnamate transferase/ hydroxy quinate transferase (HCT/HQT) was located near the bottom of LG 17, where there is a stable chlorogenic acid QTL. The predicted apple protein on LG 17 for HCT and HQT (MDP0000307780) was highly similar to artichoke HCT (86\%) and HQT1 (97\%) [21], respectively. Leucoanthocyanidin reductase 1 (LAR1) [22] was positioned at the top of LG 16 and co-located with the cluster of QTLs for flavanols. Five predicted gene models with identical positions had significant sequence similarities with $L A R 1$ in this genomic region. 
Table 2 Quantitative Trait Loci (QTLs) detected for 17 polyphenolic compounds in the 'Royal Gala' (RG) and 'Braeburn' (BB) parental genetic maps using a) MQM analysis and b) Kruskal-Wallis test.

\begin{tabular}{|c|c|c|c|c|c|c|c|c|}
\hline \multicolumn{9}{|l|}{ Table 2a } \\
\hline Compound & Tissue & Year & Parent & Linkage group & LOD score & & $\%$ variation & Marker with highest LOD \\
\hline \multirow[t]{7}{*}{ Chlorogenic acid } & Cortex & 2008 & BB & 13 & 4.00 & $* *$ & 20.1 & GDsnp00101 \\
\hline & Cortex & 2008 & BB & 17 & 3.67 & $*$ & 13.2 & GDsnp00058 \\
\hline & Cortex & 2008 & RG & 17 & 8.30 & $* * *$ & 30.5 & GDsnp01525 \\
\hline & Skin & 2008 & RG & 17 & 13.98 & $* * *$ & 46.5 & GDsnp01525 \\
\hline & Skin & 2010 & RG & 17 & 3.81 & $* *$ & 10.1 & GDsnp00178 \\
\hline & Cortex & 2010 & RG & 17 & 6.25 & $* * *$ & 16.3 & GDsnp01525 \\
\hline & Skin & 2010 & RG & 17 & 11.47 & $* * *$ & 27.8 & GDsnp01525 \\
\hline \multirow[t]{11}{*}{ p-coumaroyl quinic acid } & Cortex & 2008 & RG & 1 & 4.44 & $* * *$ & 42.4 & GDsnp02580 \\
\hline & Skin & 2010 & RG & 1 & 5.57 & $* *$ & 54.8 & GDsnp01678 \\
\hline & Skin & 2008 & BB & 6 & 3.53 & * & 12.5 & GDsnp00197 \\
\hline & Cortex & 2008 & BB & 14 & 4.82 & $* *$ & 16.2 & GDsnp01733 \\
\hline & Skin & 2008 & BB & 14 & 4.87 & $* *$ & 17.0 & GDsnp01733 \\
\hline & Cortex & 2008 & RG & 14 & 4.54 & $* * *$ & 7.1 & GDsnp01727 \\
\hline & Skin & 2008 & RG & 14 & 4.97 & $* * *$ & 19.3 & GDsnp01727 \\
\hline & Cortex & 2010 & BB & 14 & 6.78 & $* * *$ & 17.2 & GDsnp01767 \\
\hline & Cortex & 2010 & RG & 14 & 4.14 & $* *$ & 10.9 & GDsnp01727 \\
\hline & Cortex & 2008 & BB & 15 & 3.88 & * & 12.8 & GDsnp01265 \\
\hline & Cortex & 2010 & BB & 15 & 4.65 & $* * *$ & 12.8 & GDsnp00932 \\
\hline \multirow[t]{2}{*}{ Cyanidin 3-O-arabinoside } & Skin & 2008 & BB & 9 & 4.60 & $* *$ & 18.7 & GDsnp00467 \\
\hline & Skin & 2008 & RG & 9 & 6.26 & $* * *$ & 35.4 & GDsnp01107 \\
\hline \multirow[t]{4}{*}{ Cyanidin 3-O-galactoside } & Skin & 2008 & BB & 9 & 4.53 & $* *$ & 18.7 & GDsnp00467 \\
\hline & Skin & 2008 & RG & 9 & 8.34 & $* * *$ & 41.8 & GDsnp01880 \\
\hline & Skin & 2010 & BB & 9 & 8.91 & $* * *$ & 23.5 & GDsnp00452 \\
\hline & Skin & 2010 & RG & 9 & 7.30 & $* * *$ & 34.1 & GDsnp00352 \\
\hline \multirow[t]{6}{*}{ Catechin } & Cortex & 2008 & BB & 16 & 6.44 & $* * *$ & 24.5 & LAR1 \\
\hline & Cortex & 2008 & RG & 16 & 5.65 & $* * *$ & 22.3 & LAR1 \\
\hline & Cortex & 2010 & BB & 16 & 18 & $* * *$ & 41.1 & LAR1 \\
\hline & Skin & 2010 & BB & 16 & 31.26 & $* * *$ & 59.9 & LAR1 \\
\hline & Cortex & 2010 & RG & 16 & 17.62 & $* * *$ & 40.4 & LAR1 \\
\hline & Skin & 2010 & $R G$ & 16 & 30.51 & $* * *$ & 60.3 & LAR1 \\
\hline \multirow[t]{8}{*}{ Epicatechin } & Cortex & 2008 & $\mathrm{BB}$ & 16 & 18.23 & $* * *$ & 55.6 & LAR1 \\
\hline & Skin & 2008 & BB & 16 & 16.34 & $* * *$ & 51.3 & LAR1 \\
\hline & Cortex & 2008 & $R G$ & 16 & 15.53 & $* * *$ & 52.0 & LAR1 \\
\hline & Skin & 2008 & $R G$ & 16 & 14.89 & $* * *$ & 49.3 & LAR1 \\
\hline & Cortex & 2010 & BB & 16 & 35.95 & $* * *$ & 65.7 & LAR1 \\
\hline & Skin & 2010 & $\mathrm{BB}$ & 16 & 23.57 & $* * *$ & 50.1 & LAR1 \\
\hline & Cortex & 2010 & $R G$ & 16 & 32.24 & $* * *$ & 65.2 & LAR1 \\
\hline & Skin & 2010 & RG & 16 & 21.65 & $* * *$ & 48.0 & $L A R 1$ \\
\hline \multirow[t]{4}{*}{ Unknown procyanidin oligomer 1} & Cortex & 2010 & BB & 16 & 31.82 & $* * *$ & 61.2 & LAR1 \\
\hline & Skin & 2010 & BB & 16 & 41.28 & $* * *$ & 71.8 & LAR1 \\
\hline & Cortex & 2010 & RG & 16 & 30.75 & $* * *$ & 60.9 & LAR1 \\
\hline & Skin & 2010 & RG & 16 & 41.08 & $* * *$ & 71.5 & LAR1 \\
\hline \multirow[t]{4}{*}{ Unknown procyanidin oligomer 2} & Skin & 2010 & $\mathrm{BB}$ & 6 & 3.41 & * & 5.2 & GDsnp01996 \\
\hline & Cortex & 2010 & $\mathrm{BB}$ & 7 & 4.30 & $* * *$ & 14.3 & GDsnp01946 \\
\hline & Skin & 2010 & $\mathrm{BB}$ & 16 & 21.35 & $* * *$ & 46.5 & LAR1 \\
\hline & Skin & 2010 & RG & 16 & 19.13 & $* * *$ & 44.0 & LAR1 \\
\hline \multirow[t]{3}{*}{ Unknown procyanidin oligomer 3} & Cortex & 2010 & BB & 7 & 3.63 & $* *$ & 13.6 & GDsnp01946 \\
\hline & Skin & 2010 & BB & 16 & 17.15 & $* * *$ & 39.5 & LAR1 \\
\hline & Skin & 2010 & RG & 16 & 14.97 & $* * *$ & 36.4 & LAR1 \\
\hline
\end{tabular}


Table 2 Quantitative Trait Loci (QTLs) detected for 17 polyphenolic compounds in the ?'?Royal Gala?'? (RG) and ?'? Braeburn?'? (BB) parental genetic maps using a) MQM analysis and b) Kruskal-Wallis test. (Continued)

\begin{tabular}{|c|c|c|c|c|c|c|c|c|}
\hline \multirow[t]{5}{*}{ Unknown procyanidin oligomer 4} & Cortex & 2010 & $\mathrm{BB}$ & 7 & 3.24 & * & 5.2 & GDsnp01946 \\
\hline & Cortex & 2010 & BB & 16 & 28.38 & $* * *$ & 56.6 & LAR1 \\
\hline & Skin & 2010 & BB & 16 & 17.33 & $* * *$ & 39.8 & LAR1 \\
\hline & Cortex & 2010 & RG & 16 & 25.82 & $* * *$ & 55.0 & LAR1 \\
\hline & Skin & 2010 & RG & 16 & 15.27 & $* * *$ & 37.1 & LAR1 \\
\hline \multirow[t]{6}{*}{ Unknown procyanidin oligomer 5} & Cortex & 2010 & BB & 7 & 3.76 & $* * *$ & 5.0 & GDsnp01946 \\
\hline & Cortex & 2010 & BB & 14 & 3.22 & $* *$ & 6.0 & GDsnp01639 \\
\hline & Cortex & 2010 & BB & 16 & 28.3 & $* * *$ & 56.6 & LAR1 \\
\hline & Skin & 2010 & BB & 16 & 17.93 & $* * *$ & 40.9 & LAR1 \\
\hline & Cortex & 2010 & RG & 16 & 25.8 & $* * *$ & 54.8 & LAR1 \\
\hline & Skin & 2010 & RG & 16 & 15.56 & $* * *$ & 37.6 & LAR1 \\
\hline \multirow[t]{4}{*}{ Procyanidin B2 } & Skin & 2008 & $\mathrm{BB}$ & 16 & 14.14 & $* * *$ & 46.5 & LAR1 \\
\hline & Skin & 2008 & RG & 16 & 12.84 & $* * *$ & 44.5 & LAR1 \\
\hline & Skin & 2010 & BB & 16 & 16.6 & $* * *$ & 39.6 & LAR1 \\
\hline & Skin & 2010 & RG & 16 & 15.59 & $* * *$ & 37.6 & LAR1 \\
\hline Quercetin 3-O-arabinofuranoside & Skin & 2008 & RG & 9 & 3.98 & $* * *$ & 20.6 & GDsnp00045 \\
\hline \multirow[t]{2}{*}{ Quercetin 3-O-glucoside } & Skin & 2010 & RG & 1 & 3.14 & * & 39.9 & GDsnp01678 \\
\hline & Skin & 2010 & $R G$ & 14 & 3.03 & * & 26.4 & GDsnp01522 \\
\hline \multirow[t]{2}{*}{ Quercetin 3-O-rutinoside } & Skin & 2008 & RG & 17 & 3.24 & $* * *$ & 12.8 & GDsnp00178 \\
\hline & Skin & 2010 & RG & 17 & 3.17 & ** & 8.4 & GDsnp01842 \\
\hline Quercetin 3-O-xyloside & Skin & 2008 & RG & 17 & 3.73 & $* * *$ & 14.7 & GDsnp02075 \\
\hline Phloridzin-xyloside & Skin & 2010 & RG & 17 & 3.89 & $* *$ & 10.3 & GDsnp00262 \\
\hline \multicolumn{9}{|l|}{ Table $2 b$} \\
\hline Compound & Tissue & Year & Parent & Linkage group & Marker & $K$ & & \\
\hline \multirow[t]{2}{*}{ Procyanidin B2 } & Cortex & 2008 & $\mathrm{BB}+\mathrm{RG}$ & 16 & LAR1 & 43.2 & & \\
\hline & Cortex & 2010 & $\mathrm{BB}+\mathrm{RG}$ & 16 & LAR1 & 61.9 & & \\
\hline Unknown procyanidin oligomer 2 & Cortex & 2010 & $\mathrm{BB}+\mathrm{RG}$ & 16 & LAR1 & 95.3 & & \\
\hline Unknown procyanidin oligomer 3 & Cortex & 2010 & $\mathrm{BB}+\mathrm{RG}$ & 16 & LAR1 & 83.2 & & \\
\hline
\end{tabular}

Significance of the QTL at the genome-wide level was tested using 1,000 permutations: *: 90\%, **: 95\% and ***: $99 \%$.

PCR primers were developed from genomic sequences for both $L A R 1$ and $H C T / H Q T$, to enable the candidates to be mapped genetically with respect to the respective QTLs. Anthocyanidin synthase (ANS), located on LG 6 within a QTL from 'Braeburn' for $p$-coumaroyl quinic acid in the fruit skin, was found in 2008 only.

Seven candidate genes were positioned on linkage groups with no associated QTLs: PAL, F3H, ANR, FLS, $C 4 H, 4 C L$ and $D F R$. Eight of the candidate genes were positioned on linkage groups where some QTLs were detected; however, most of these candidate genes did not locate within the QTL intervals, or if they colocated there was not an obvious functional biosynthetic pathway correlation between the candidate gene and the compound for which the QTLs were identified.

The high resolution melting (HRM)-based genetic marker for HCT/HQT mapped at the bottom of LG 17 of the 'Braeburn' parental map. Location of the candidate gene within the QTL interval was hence determined based on alignment of the 'Braeburn' map with the 'Royal Gala' map (Additional File 3; figure S2).
The HRM-based genetic marker for LAR1 that mapped at the top of LG 16 was fully informative, segregating ef $\mathrm{x} e g$, and it could be employed for QTL detection in both parental maps. The PCR primers for this polymorphic marker were positioned in the fourth intron of LAR1. This marker had the highest LOD score for all eight flavanol compounds in both parental maps (Table 2a). MQM analysis with LAR1 as a cofactor revealed no other QTL within the LG 16 region or anywhere else in the genome. The $f$ and $g$ alleles for 'Royal Gala' and 'Braeburn', respectively, were associated with higher concentration of flavanols. The individuals carrying the homozygous ee genotype exhibited significantly lower concentrations of flavanol compounds in the fruit skin and no flavanol was detected in the fruit cortex (Figure 3).

A comprehensive search of the $1.2 \mathrm{Mb}$ genomic region spanning the flavanol QTL cluster on LG 16 was performed to ascertain whether candidate genes other than LAR1 are also located within this QTL interval. In total, 93 apple predicted genes with supporting cDNA 


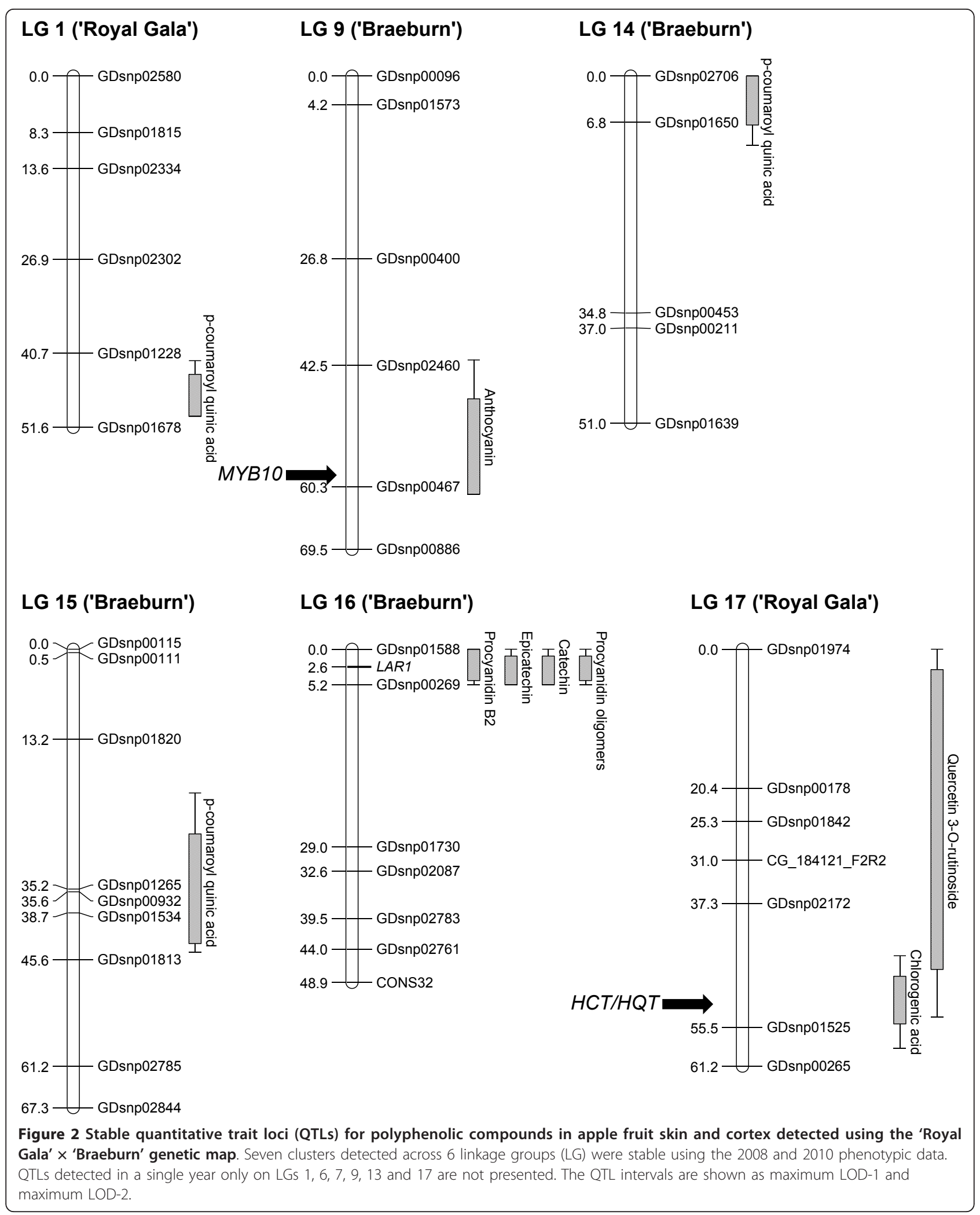


Table 3 Candidate genes for control of fruit polyphenolic content found in the apple gene prediction set (Additional File 2; figure S1).

\begin{tabular}{|c|c|c|c|c|c|}
\hline Symbol & Gene name & Genbank accession & Apple gene prediction & LG & Position (kb) \\
\hline \multirow[t]{2}{*}{ PAL } & phenylalanine ammonia lyase & ES790093 & MDP0000191304 & 4 & 8,075 \\
\hline & & & MDP0000388769 & 12 & 15,419 \\
\hline \multirow[t]{2}{*}{$\mathrm{C} 4 \mathrm{H}$} & cinnamate 4-hydroxylase & EB139247 & MDP0000229348 & 11 & 5,193 \\
\hline & & & MDP0000225698 & 3 & 5,531 \\
\hline \multirow[t]{2}{*}{ HCT/HQT } & hydroxycinnamoyl CoA shikimate/quinate hydroxycinnamoyl transferase & AM690438 & MDP0000264424 & 9 & 27,594 \\
\hline & & (artichoke HQT1) & MDP0000307780 & 17 & 19,929 \\
\hline \multirow[t]{2}{*}{$\mathrm{C} 3 \mathrm{H}$} & p-coumarate 3-hydroxylase & NP_850337 & MDP0000466557 & 8 & 35,073 \\
\hline & & & MDP0000836708 & 15 & 53,887 \\
\hline \multirow[t]{3}{*}{$\mathrm{CHS}$} & chalcone synthase & AB074485 & MDP0000686661 & 9 & 16,919 \\
\hline & & & MDP0000686666 & 9 & 16,932 \\
\hline & & & MDP0000302905 & 14 & 26,679 \\
\hline \multirow[t]{3}{*}{$\mathrm{CHI}$} & chalcone isomerase & CN946541 & MDP0000759336 & 14 & 12,382 \\
\hline & & & MDP0000682953 & 1 & 20,836 \\
\hline & & & MDP0000205890 & 11 & 19,398 \\
\hline \multirow[t]{2}{*}{$\mathrm{F} 3 \mathrm{H}$} & flavanone 3-hydroxylase & AB074486 & MDP0000704377 & 2 & 11,905 \\
\hline & & & MDP0000139343 & 5 & 23,797 \\
\hline \multirow[t]{2}{*}{$F 3^{\prime} H$} & flavanone 3'-hydroxylase & ACR14867 & MDP0000190489 & 6 & 26,649 \\
\hline & & & MDP0000286933 & 14 & 31,156 \\
\hline \multirow[t]{2}{*}{$D F R$} & dihydroflavonol reductase & AF117268 & MDP0000494976 & 12 & 26,022 \\
\hline & & & MDP0000440654 & 8 & 4,393 \\
\hline ANS & anthocyanidin synthase (LDOX) & AF117269 & MDP0000360447 & 6 & 17,129 \\
\hline \multirow[t]{2}{*}{ UFGT } & UDP-glucose flavonoid 3-O-glucosyl transferase & AF117267 & MDP0000376418 & 9 & 31,316 \\
\hline & & & MDP0000706999 & 7 & 14,018 \\
\hline$F L S$ & flavonol synthase & EB137300 & MDP0000260404 & 8 & 17,498 \\
\hline \multirow[t]{2}{*}{$L A R$} & leucoanthocyanidin reductase & AY830131 & MDP0000376284 & 16 & 1,536 \\
\hline & & AY830132 & MDP0000140621 & 13 & 2,849 \\
\hline \multirow[t]{2}{*}{ ANR } & anthocyanidin reductase (Banyuls) & DQ099803 & MDP0000243194 & 5 & 2,430 \\
\hline & & & MDP0000494976 & 12 & 26,022 \\
\hline \multirow[t]{2}{*}{ GT1 } & glucosyl transferase & EB124403 & MDP0000146703 & 1 & 14,114 \\
\hline & & & MDP0000875654 & 7 & 19517 \\
\hline GT2 & glucosyl transferase & EB141701 & MDP0000316379 & 14 & 16,678 \\
\hline
\end{tabular}

The approximate physical position on the apple linkage group (LG) is given in kilobases (kb) from the top of the LG.

sequences were identified between $0.8 \mathrm{Mb}$ to $2.0 \mathrm{Mb}$ on LG 16 (Additional File 5; figure S4). Of these, 12 had possible regulatory or direct effects on polyphenolic biosynthesis (Table 4) and included transcription factors of the classes zinc-finger $\mathrm{C} 2 \mathrm{H} 2$, CONSTANS-like, AP2 bZIP, bHLHs, MYBs and MYB-related.

We compared the flavanol compounds content of individuals from the 'Royal Gala' × 'Braeburn' segregating population with commercial cultivars, as well as two related species with extreme polyphenolic content: quince and a crab apple (Figure 4). Quince (Cydonia oblonga) was at the low extreme of epicatechin content, far below that found for the lowest member of the 'Royal Gala' × 'Braeburn' segregating population, while the highest epicatechin concentration in the 'Royal Gala' $\times$ 'Braeburn' progeny was about the same as that in crab apple (Malus hybrida 'Oekonomierat Echtermeyer').
Nevertheless, the apple 'Royal Gala' $\times$ 'Braeburn' progeny with the less favourable allele of LAR1 (ee) was always low.

\section{Discussion}

Variation in concentration of polyphenolic compounds concentrations in a segregating apple population

The twenty-five fruit polyphenolics compounds analysed by UHPLC varied greatly in concentration among progenies in the 'Royal Gala' $\times$ 'Braeburn' segregating population, indicating that there is a serious risk that the process of breeding could rapidly decrease concentrations of nutraceutical compounds positively associated with human health through selection for linked negatively correlated traits. While the parents of our mapping population (both current commercials cultivars) are moderate in their polyphenolic concentrations, apple germplasm exists 


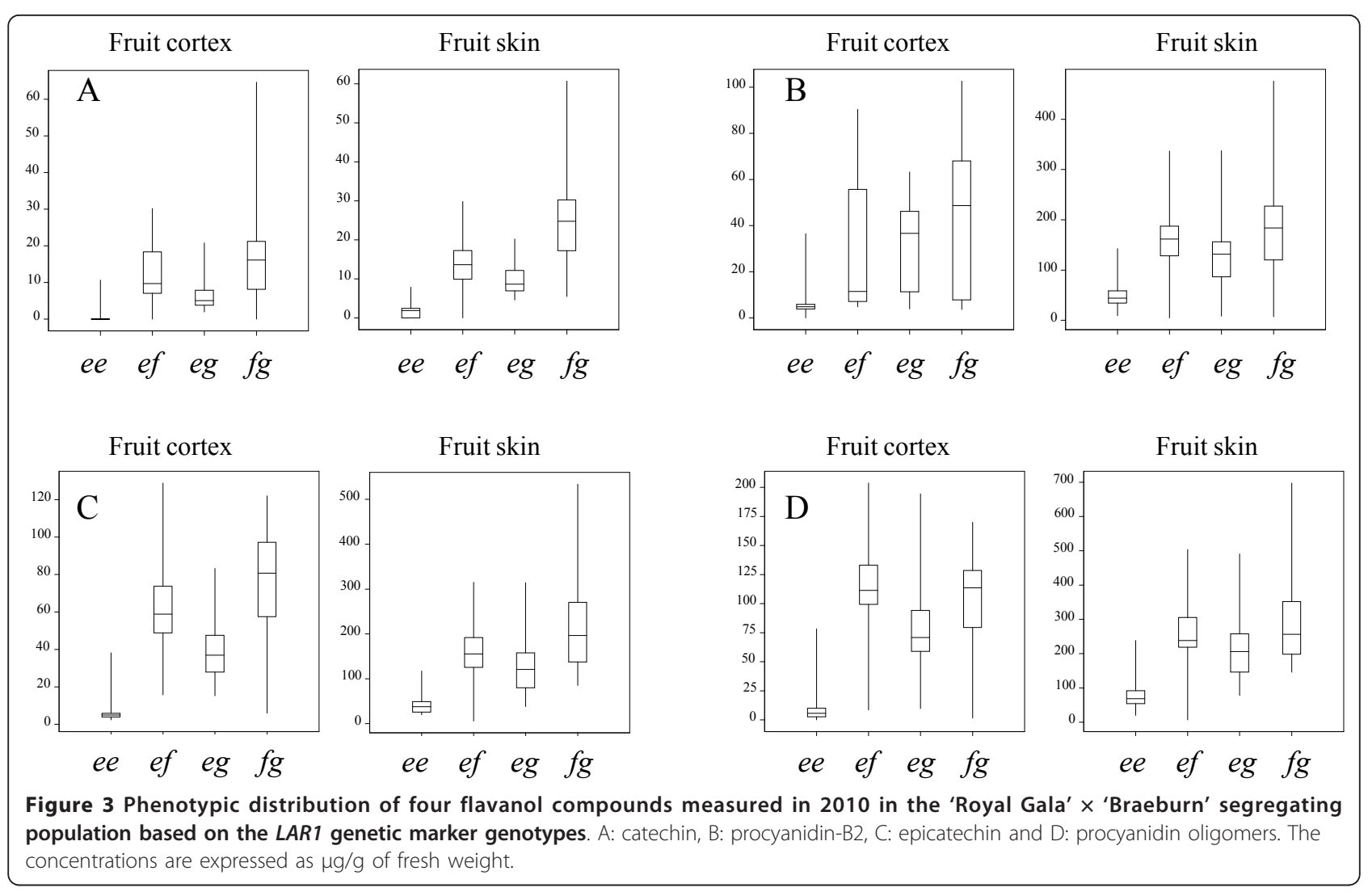

Table 4 Positional candidate genes located in the LG 16 QTL interval for fruit flavanol content detected in the 'Royal Gala' × 'Braeburn' segregating population.

\begin{tabular}{|c|c|c|c|c|}
\hline Identifier & $\begin{array}{l}\text { Best } \\
\text { Arabidopsis } \\
\text { match }\end{array}$ & Possible function & $\begin{array}{l}\text { Position } \\
\text { (kb) }\end{array}$ & Gene ID \\
\hline $\mathrm{C} 2 \mathrm{H} 2 \mathrm{TF}$ & AT3G18290 & $\begin{array}{l}\text { RING finger and CHY zinc finger encoding BRUTUS (BTS), E3 ligase protein with metal } \\
\text { ion binding and DNA binding domains, which negatively regulates the response to iron } \\
\text { deficiency }\end{array}$ & 1,000 & MDP0000283750 \\
\hline $\mathrm{C} 2 \mathrm{H} 2 \mathrm{TF}$ & AT1G68360 & $\mathrm{C} 2 \mathrm{H} 2$ and $\mathrm{C} 2 \mathrm{HC}$ zinc finger family & 1,020 & MPD0000183099 \\
\hline MdMYBT & AT1G68320 & $\begin{array}{l}\text { MYB involved in regulation of phosphate starvation responses and gibberellic acid } \\
\text { biosynthesis. }\end{array}$ & 1,070 & MDP0000659260 \\
\hline$b H L H$ & AT1G25330 & bHLH75, BR enhanced & 1,080 & MDP0000725991 \\
\hline COL & AT1G68520 & Contans-like light regulation of secondary metabolites & 1,220 & MDP0000185616 \\
\hline$b Z I P$ & AT1G68640 & $\mathrm{HBP}-1 \mathrm{~b}(\mathrm{c} 1), \mathrm{BZIP}-\mathrm{PAN}$ is essential for AG activation in early flowering & 1,380 & MDP0000250967 \\
\hline$M d G 2 L 6$ & AT1G25550 & Golden-like ARR18 MYB-related & 1,440 & MDP0000202657 \\
\hline $\begin{array}{l}\text { MdAP2D36 } \\
\text { TF }\end{array}$ & AT1G68840 & $\begin{array}{l}\text { Regulator of vac ATPase Rav2 is part of a complex that has been named 'regulator of } \\
\text { the }(H+) \text {-ATPase of the vacuolar and endosomal membranes' (RAVE) }\end{array}$ & 1,480 & MDP0000939633 \\
\hline LAR1 & & MdLAR1 & 1,540 & MDP0000376284 \\
\hline bHLH & AT1G68810 & Known bHLH, no other function & 1,550 & MDP0000319726 \\
\hline bHLH & AT1G68920 & bHLH49 Known bHLH, no other function & 1,890 & MDP0000154272 \\
\hline $\mathrm{MdbHLH} 21$ & AT1G69010 & BES1-INTERACTING MYC-LIKE PROTEIN 2 & 1,970 & MDP0000149222 \\
\hline
\end{tabular}

The approximate physical position on the apple linkage group (LG) is given in kilobases (kb) from the top of the LG calculated using assembled metacontigs of the apple genome sequence [20]. 


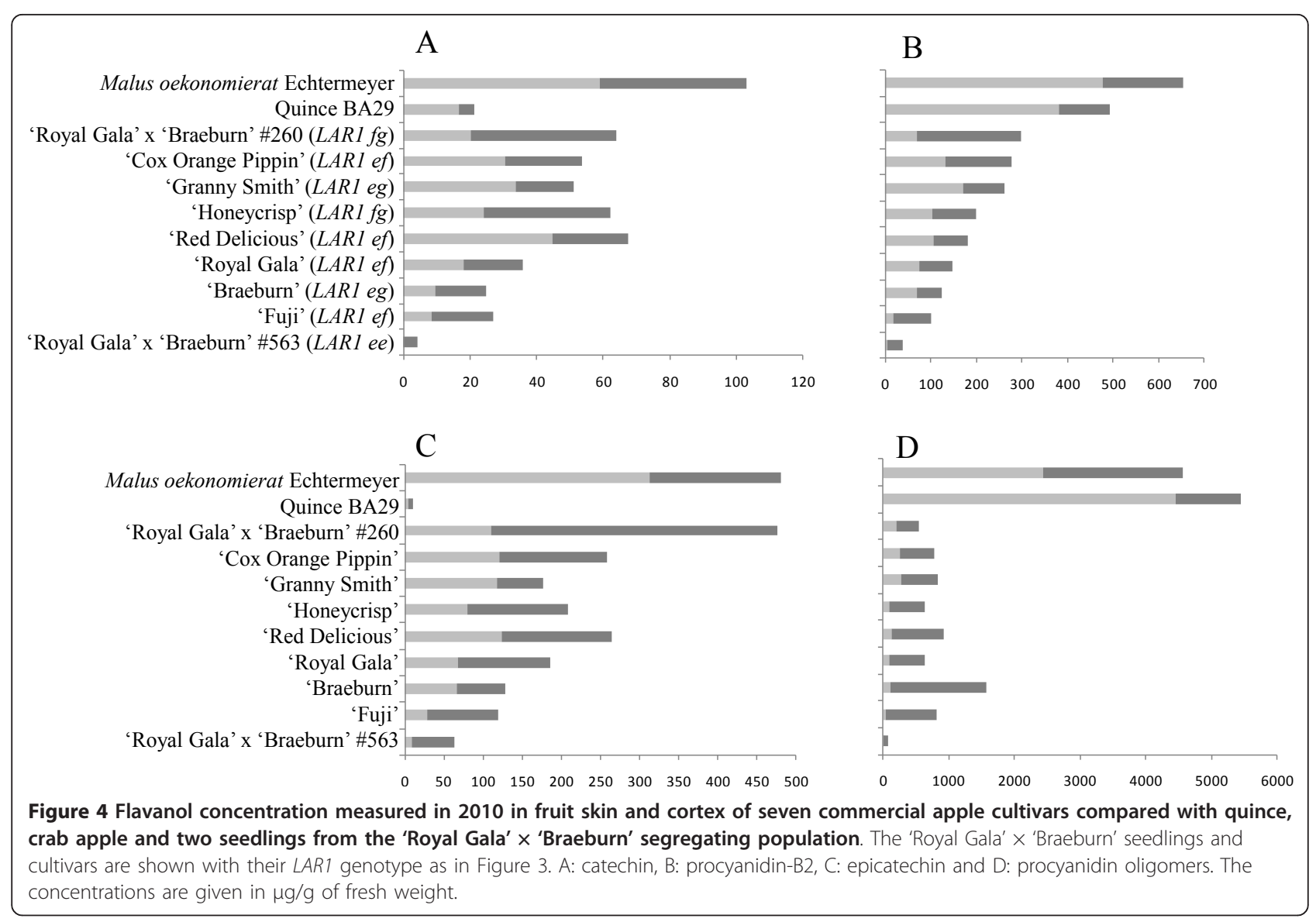

with far higher concentrations (Figure 4, [2]), indicating the opportunity to raise or lower polyphenolic concentration by breeders. Differences were observed in polyphenolics concentrations in the 'Royal Gala' $\times$ 'Braeburn' segregating population between 2008 and 2010. These differences are likely to be due to variations in climatic conditions between both years.

\section{QTLs for polyphenolic compounds}

Our mapping of QTLs for polyphenolic compounds in fruit from the 'Royal Gala' × 'Braeburn' segregating population has added considerably to the body of knowledge concerning the genetic architecture of the control of antioxidant content in apple, previously limited to mapping of QTLs for ascorbate [4], fruit skin anthocyanic colouration [23] and a major locus for fruit cortex anthocyanin content [17]. Seven QTL clusters were stable across two years of harvest and spanned a total of 65 individual QTLs that were highly significant and included loci for content of flavanols, flavonols, anthocyanins and hydroxycinnamic acids. Although the further 14 QTLs putatively controlling concentration for eight polyphenolic compounds detected from either 2008 or 2010 fruit harvests still require verification, their number indicates the complexity of control of biosynthesis in apple fruit of compounds contributing to human health and points towards the influence of environmental as well as genetic factors.

A QTL cluster for skin anthocyanins was detected at the bottom of LG 9, in the region where a major locus for skin colouration was mapped earlier using a sequence characterized amplified region (SCAR) marker $[24,25]$. It has also been demonstrated that MYB1 is involved in skin colouration [23]. Our finding confirms these observations.

A QTL cluster for chlorogenic acid co-located with the HCT/HQT gene. Chlorogenic acid is the most concentrated polyphenolic compound in the fruit cortex of the apples from the 'Royal Gala' × 'Braeburn' segregating population. Moreover, chlorogenic acid has a strong antioxidant activity, which makes it of primary importance for the health benefit of apple. $H C T$ and $H Q T$ have been demonstrated to contribute to the synthesis of chlorogenic acid in coffee [26] and artichoke [21,27]. Nevertheless, the $H C T$ and $H Q T$ genes remain to be described in apple and further work is required to confirm the involvement of these genes and their variants, to determine the fruit concentration of chlorogenic acid. 
This includes developing a $H C T / H Q T$ marker for 'Royal Gala' to confirm that the QTL is strongly linked to this trait and studying these genes' expression during fruit development of cultivars with varying concentrations of hydroxycinnamic acids.

The large effect LG 16 QTL cluster controlling the concentrations of fruit catechin, epicatechin, procyanidin oligomers and procyanidin $\mathrm{B} 2$ co-locates with LAR1, a candidate gene encoding the enzyme that catalyses the conversion of leucoanthocyanidins into catechin, upstream in the biosynthetic pathway of polymerised procyanidins (Additional File 3; figure S2). Twelve genes coding for transcription factors of several classes that could possibly regulate $L A R 1$ are also located within this genomic region. Further work is required to determine whether the effect is through changes in gene regulation or through changes in the biochemical functionality of the enzyme encoded by LAR1. To this end, we have initiated a study of the pattern of LAR1 expression in extreme phenotypes in the mapping population as well as in a range of apple germplasm accessions. LAR1 was demonstrated to be expressed in green and red skin of 'Cripp's Red' during fruit development [22], with higher expression at the early stage of fruit development. However, this study was carried out only in one cultivar. In addition to LAR1, mRNA expression of the transcription factors located in the QTL intervals will be carried out in our study. A control of flavanol compounds concentration by LAR1 would contrast with the case of anthocyanin content, where it has been shown that control is exerted at the transcription level [19], through activation of the enzymes of the anthocyanin biosynthesis pathway by MYB10, through a WD40-bHLH-MYB protein complex. Our favoured hypothesis is that the mutation is in the promoter region of $L A R 1$, in a site recognised by the transcription factors regulating it. We believe that it is likely that the variation is not a complete loss of function of $L A R 1$, as tannins have a recognized role in the response of plants to biotic and abiotic stress and although there is another copy of the LAR gene (LAR2) located on LG13, it not appear co-locate with any flavanol QTL.

While our QTL mapping study does not provide definitive proof that LAR1 controls the variation in the concentration of flavanols in the fruit cortex and skin, recent functional evidence using gene silencing of $M d A N S$ strengthens this hypothesis. ANS uses leucoanthocyanidins in competition with LAR and synthesizes anthocyanidins that are converted into either anthocyanins via UFGT or epicatechin via ANR. The silencing of MdANS suppressed red colouration of a red-leaved apple cultivar and significantly increased the concentrations of other polyphenolic compounds, such as hydroxycinnamic acids, catechin and epicatechin in the transgenic plants [28]. While ANS is not involved in the synthesis of hydroxycinnamic acids, we found that it co-locates with a QTL for q-coumaroyl quinic acid. Although this QTL was only found in 2008, our results suggest that $A N S$ controls this trait variation. The results of Szankowski and colleagues suggested an alternative pathway for the synthesis of epicatechin by epimerisation or by non-stereospecific depolymerisation of procyanidin oligomers [28]. Our findings that epicatechin and catechin are both positively correlated $(0.77$ and 0.65 in skin and cortex, respectively), that the QTLs for both compounds co-locate with $L A R 1$ and that the alleles of $L A R 1$ have the same effect for concentrations of both compounds reinforce the hypothesis by Szankowski and colleagues of an alternative pathway for epicatechin.

The allele-specific genetic marker developed from LAR1 is an excellent candidate for use in marker assisted selection for increased flavanol content, as the LG 16 QTL is stable across years and present in parental maps of 'Braeburn' and 'Royal Gala', cultivars which play a significant role in the New Zealand and other apple breeding programmes internationally. Furthermore a similarly located QTL was identified in a segregating population from a 'Prima' $\times$ 'Fiesta' cross (S. Khan and $H$. Schouten, personal communication), indicating that the LG 16 QTL is carried by a range of other commercial apple cultivars that are used as breeding parents. The use of this gene-based marker for selection for fruit flavanol content is particularly important, because phytochemical compounds are not usually measured by breeders when they perform seedling phenotype assessment during the initial steps of selection that involve controlled crosses over one on more generations, but are only evaluated in released commercial cultivars, when it is too late to influence the final breeding outcome. We suggest that the LAR1 marker should be screened over the parents for the original cross, as well as progeny from all generations, to ensure that breeding parents at all stages carry either or both favourable alleles of LAR1.

In addition, it is useful to investigate the links between flavanol concentration and current breeding traits. While flavanols have been suggested to be beneficial to human health as a source of antioxidants, they are also associated with astringency, which is not preferred by consumers. We are hence planning an organoleptic analysis of fruit from the 'Royal Gala' $\times$ 'Braeburn' population to determine whether astringency is correlated with the flavanol concentration. It is known that the LG 16 QTL cluster co-locates with a major locus for fruit acidity (malic acid) identified from a 'Prima' $\times$ 'Fiesta' population [25,29] and that acidity is important in determining consumer preferences [30]. In addition, 
QTLs for loss of fruit firmness during storage and date of budbreak have been mapped to the same region of LG 16 in the 'Royal Gala' × 'Braeburn' population (D. Chagné, unpublished). There is thus a real risk of selecting for a mix of positive and negative traits if the LAR1 gene marker is used in isolation. Identification of the functional allele of gene markers for each trait mapping to this region (as we have done for flavanols with LAR1) will enable selection of the few genetically elite progeny that carry the most desirable combination of traits from large breeding populations.

\section{Conclusion}

We have detected stable QTLs for polyphenolic antioxidant content in apple and have provided strong evidence that a polymorphism linked to a biosynthetic enzyme for flavanols (LAR1) controls the concentration of flavanols in the fruit skin and cortex, and evidence that a polymorphism linked to $H Q T / H C T$ may control the concentrations of chlorogenic acid. These candidate genederived markers have potential to facilitate the development of new apple cultivars bearing fruit with increased concentrations of a range of polyphenolic compounds with human health-benefit.

\section{Methods}

Plant material, fruit sampling and polyphenolic extraction In 2005, 590 seedlings from a 'Royal Gala' × 'Braeburn' segregating $F_{1}$ population were grafted on 'M.27' dwarfing rootstocks at the Plant \& Food Research Clyde research orchards (Central Otago, New Zealand). Two replicates for each tree were planted at random, $5 \times 1.5$ $\mathrm{m}$ apart in an east-west orientation. The parents 'Royal Gala' and 'Braeburn' were also planted at random in the same block. Trees were regularly irrigated to avoid water deficit, and pests and diseases were controlled by conventional techniques in line with professional practices.

Fruit were picked at maturity based on background colour and blush development followed by a confirmatory starch iodine test between mid February and end of April in 2008 and 2010. A total of 120 and 170 genotypes were sampled in 2008 and 2010, respectively. Six apples were randomly harvested from each tree. The fruit were processed within two to three days of picking. Each apple was cut into four quarters longitudinally through the axis of the core and four thin segments $(\sim 5$ $\mathrm{mm}$ wide at the skin side, tapering to nothing above the core) from were taken from the four quarters of each of the six apples per tree. The skin was removed from each segment to create a separate sample from the cortex. The 24 skin pieces and the 24 cortex pieces from the six apples were bulked separately, frozen immediately in liquid nitrogen and then ground in liquid nitrogen to a fine powder.

Approximately $100 \mathrm{mg}$ of this powder was suspended in $1 \mathrm{ml}$ of extraction solvent (ethanol/water/formic acid, $80: 20: 1, \mathrm{v} / \mathrm{v} / \mathrm{v})$. Each sample was homogenised for 1 minute using a Heidolph ${ }^{\circledR}$ vortex-shaker, Reax 2000 (Heidolph Instruments GmbH, Schwabach, Germany), then stored at $4^{\circ} \mathrm{C}$ for 24 hours before being centrifuged at $1000 \mathrm{~g}$ for $10 \mathrm{~min}$ using a Jouan ${ }^{\circledR}$ Hema-C centrifuge (Jouan, Saint Herblain, France). $180 \mu \mathrm{l}$ of the clear supernatant was transferred to a 96-well plate for analysis by reverse-phase UHPLC. A duplicate was included every ten samples to evaluate the reproducibility.

\section{UHPLC analysis of fruit polyphenolics}

The UHPLC system used to analyse polyphenolics was a Dionex Ultimate ${ }^{\circledR} 3000$ Rapid Separation LC system equipped with a SRD-3400 solvent rack with four degasser channels, HPR-3400RS binary pump, WPS-3000RS thermostated autosampler, TCC-3000RS thermostated column compartment, and DAD-3000RS Diode Array Detector for monitoring at all wavelengths from 190 to $800 \mathrm{~nm}$. The analytical column used was a Kinetex ${ }^{\mathrm{TM}}$ C18 $1.7 \mu \mathrm{m}, 100 \times 2.1 \mathrm{~mm}$ (Phenomenex ${ }^{\circledR}$ NZ Ltd., Milford, Auckland City, New Zealand) maintained at $45^{\circ}$ C. The injection volume for the extract was $0.5 \mu \mathrm{l}$. Linear gradient elution was performed with Solution A ( $0.5 \%$ phosphoric acid in water) and solution B (acetonitrile) delivered at a flow rate of $0.75 \mathrm{ml} / \mathrm{min}$ as follows: isocratic elution $5 \% \mathrm{~B}, 0-0.5 \mathrm{~min}$; linear gradient from $5 \%$ B to $25 \%$ B, $0.5-4$ min; to $95 \%$ B, $4-4.8 \mathrm{~min}$; to $100 \%$ $\mathrm{B}, 4.8-6 \mathrm{~min}$; isocratic elution $100 \% \mathrm{~B}, 6-6.5 \mathrm{~min}$; linear gradient to $5 \% \mathrm{~B}, 6.5-7 \mathrm{~min}$, to return at the initial conditions before another sample injection at $9 \mathrm{~min}$. Spectral data were collected for the entire run, and the polyphenolic components were quantified by extracting chromatograms at 210, 280, 310, 370 and $530 \mathrm{~nm}$. Catechin, epicatechin and procyanidins were quantified using chromatograms extracted at $210 \mathrm{~nm}$; quercetin, phloridzin and phloridzin-xyloside at $280 \mathrm{~nm}$; $p$-coumaroyl quinic acid at $310 \mathrm{~nm}$; quercetin glycosides and chlorogenic acid at $370 \mathrm{~nm}$; and cyanidin glycosides at $530 \mathrm{~nm}$. Chromatographic data were collected and manipulated using the Chromeleon ${ }^{\circledR}$ Chromatography Management System version 6.8. External calibration curves were constructed for epicatechin, catechin, phloridzin, quercetin, quercetin 3-O-rutinoside, cyanidin 3-O-glucoside, chlorogenic acid, procyanidin $\mathrm{B} 2$, and $p$-coumaroyl quinic acid using standards from Extrasynthese, Genay, France. Components for which standards were not available were quantified using the standard curve of a related compound. All the cyanidin glycosides were quantified using the calibration curve for cyanidin 3-O- 
glucoside. Quercetin glycosides were quantified using the calibration curve for quercetin 3-O-rutinoside, phloridzin-xyloside was quantified using the calibration curve for phloridzin, and unknown procyanidins were quantified using the calibration curve for epicatechin.

The initial polyphenolic concentrations were calculated in $\mu \mathrm{g} / \mathrm{ml}\left(\mathrm{C}_{\mathrm{v}}\right)$. Concentrations $\left(\mathrm{C}_{\mathrm{w}}\right)$ in $\mu \mathrm{g} / \mathrm{g}$ of fresh weight are obtained using the following formula:

$\mathrm{C}_{\mathrm{W}}(\mu \mathrm{g} / \mathrm{g}$ of $\mathrm{FW})=\left[\mathrm{C}_{\mathrm{v}}(\mu \mathrm{g} / \mathrm{ml}) \times\right.$ corrected volume $\left.(\mathrm{ml})\right] /$ sample weight $(\mathrm{g})$.

Because apples contain on average $85 \%$ water, a corrected volume was calculated as:

Corrected volume $(\mathrm{ml})=$ extraction solvent volume $(\mathrm{ml})+[0.85 \times$ sample weight $(\mathrm{g})]$.

Identification of the polyphenolic compounds in the Malus germplasm set was performed using a Dionex Ultimate 3000 system (Sunnyvale, CA) equipped with a diode array detector (DAD). A $5 \mu \mathrm{L}$ aliquot was injected onto a Dionex C18 Acclaim PolarAdvantage II column $(150 \times 2.1 \mathrm{~mm}$ i.d.; $3 \mu \mathrm{m}$ particle size) (Sunnyvale, CA). The mobile phases were (A) water with $0.1 \%$ formic acid and (B) acetonitrile with $0.1 \%$ formic acid. The flow rate was $0.35 \mathrm{~mL} \mathrm{~min}^{-1}$, and the column temperature was $35^{\circ} \mathrm{C}$. The $42 \mathrm{~min}$ gradient was as follows: 0-5 min, 0-8\% B; 5-10 min, 8-15\% B; 10-20 min, 15-20\% B; 20-27 min, 20\% B linear; 27-34 min, 27-100\% B; 34-36 min, $100 \%$ B linear; $36-42$ min, 0\% B, re-equilibration time. Simultaneous monitoring was set at $254 \mathrm{~nm}, 280 \mathrm{~nm}$, and $320 \mathrm{~nm}, 520 \mathrm{~nm}$ for quantification. Polyphenol compounds were identified by their retention time and spectral data compared with standards, and were quantified using five-point calibration curves.

\section{DNA extraction and SNP marker development}

Genomic DNA was extracted from young leaves from the parents and the 590 seedlings of the 'Royal Gala' $\times$ 'Braeburn' segregating population using the Qiagen Plant DNeasy Plant Mini kit (Qiagen, Hilden, Germany) following the manufacturer's protocol. Ten nanograms of genomic DNA from each sample were then amplified by whole genome amplification (WGA; [31] using the GenomiPhi V2 DNA Amplification Kit (GE Healthcare, Little Chalfont, Buckinghamshire, United Kingdom). A subset of the 951 single nucleotide polymorphism (SNP) markers used for anchoring the 'Golden Delicious' genome sequence to a genetic map [20] was selected for mapping on the basis of even distribution along the 'Golden Delicious' pseudo-chromosomes. SNPlex ${ }^{\mathrm{TM}}$ (Applied Biosystems Inc., Foster City, CA) genotyping assays [32] were carried out using $1 \mu \mathrm{l}$ (from 45 to 225 ng) of WGA-DNA according to the manufacturer's protocol. Samples were run on a 3730xl DNA Analyzer (Applied Biosystems Inc.) and data were analysed using the Gene Mapper v.4.0 software (Applied Biosystems Inc.). Genotype analysis was performed according to the SNPlex_Rules_3730 method, in accordance with the manufacturer's default settings.

\section{Genetic map construction and QTL Analysis}

Parental genetic maps were constructed using the double pseudo testcross mapping strategy [33]. The linkage analysis and the map construction were performed using JoinMap ${ }^{\circledR}$ v3.0 [34] with a LOD score of 5 for grouping and Kosambi's function for genetic distance calculation. QTL analysis was performed with MapQTL ${ }^{\circledR}$ version 5.0 [35]. The data distribution was verified for each compound before the QTL analysis: non-normal and normal distributions were analysed using a nonparametric (Kruskal-Wallis test) and an interval mapping (IM) analysis, respectively. For the IM analysis, the LOD threshold for significance of a QTL was calculated at the genome level using 1,000 permutations. Only the QTLs with a LOD score significant at greater than $90 \%$ genome-wide were retained. The most significant marker for each QTL was then used as a cofactor for a multiple QTL analysis (MQM) for detecting minor QTLs that were hidden by the major QTL in the previous IM analysis.

\section{Candidate gene detection}

Seventeen candidate genes were selected based on their involvement in the polyphenolic biosynthetic pathway (Additional File 3; Figure S2). The sequences of the candidate genes were retrieved from Genbank and a BLAST search performed against the apple gene set predicted from the whole genome sequence of 'Golden Delicious' [20]. The position of each candidate gene was recorded based on its physical position on the apple genome pseudo-chromosomes and then compared in silico to the QTL positions. The positions were calculated using assembled metacontigs of the apple genome sequence [20] separated by arbitrary gaps of $200 \mathrm{~kb}$. Candidate genes co-locating with QTLs in silico were used to develop polymorphic markers for genetic mapping, to confirm their co-location with QTLs.

\section{Candidate gene-based marker development and mapping} PCR primers were designed based on the genome assembly contig sequence [20] containing the candidate gene using Primer3 v0.4.0 http://frodo.wi.mit.edu/primer3/. The design criteria were: a final product size ranging from 100 to $150 \mathrm{bp}$; a primer size ranging from 18 to $27 \mathrm{bp}$ (optimum: $20 \mathrm{bp}$ ); a primer melting temperature ranging from $57^{\circ} \mathrm{C}$ to $63^{\circ} \mathrm{C}$ (optimum: $60^{\circ} \mathrm{C}$ ); and a percentage of $\mathrm{G}$ and $\mathrm{C}$ bases ranging from $40 \%$ to $55 \%$. The self complementarity and the 3 ' self complementarity were set to a maximum of 4 and 1 , respectively, in 
order to prevent the formation of primer dimers during PCR. The primers obtained (LAR1_MDC000496.351_F2: TGGTTCCCTGTATCCAAGTTTT, LAR1_MDC000496.351_R2: ACCTGAGATCGGTGT CCTTC, HCT_F2: TGGATGTATAGGTTAGAGAA TGTGG and HCT_R2: GCCATTGCTAGATTGAC TTTTC) were submitted to a BLASTN analysis against the apple genome assembly to guard against annealing to multiple locations.

The high resolution melting (HRM) technique performed on a LightCycler ${ }^{\circledR} 480$ (Roche) was used to detect sequence polymorphisms [36]. Polymorphic markers were screened over the 'Royal Gala' $\times$ 'Braeburn' segregating population and used to construct a new genetic map using the same parameters described earlier.

\section{Additional material}

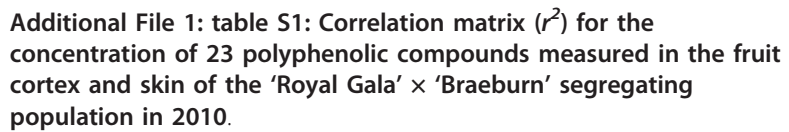

Additional File 2: figure S1: Phenotypic districtubtion of polyphenolics compounds detected in fruit skin and cortex of the 'Royal Gala' × 'Braeburn' segregating population in 2008 and 2010. Additional File 3: figure S2: Framework genetic map of 'Royal Gala' and 'Braeburn' used for QTL analysis of polyphenolic compounds in apple fruit skin and cortex.

Additional File 4: figure S3: A simplified schematic of the polyphenolics synthesis pathway. Gene symbols are identified in Table 3.

Additional File 5: figure S4: Apple gene predictions found in the QTL interval for flavanol concentration. The figure is depicted as a set of GBrowser tracks showing the position on LG 16 (top track), close up position (second and third tracks), apple genome assembly contigs (fourth track), IASMA predicted apple gene set and apple CDNA sequences (fifth track; Malus Bioview ${ }^{\mathbf{T M}^{\mathbf{T}}}$ ) [37] mapping to the region (positioned using GMAP). Gene names are indicated where known.

\section{Acknowledgements}

This work was supported by a Pipfruit Internal Investment Programme (PIIP) grant from the New Zealand Institute for Plant \& Food Research Limited. The authors thank Dr John McCallum for critical reviews of the manuscript. This work is dedicated to the memory of Jenny Fraser.

\section{Author details}

'The New Zealand Institute for Plant \& Food Research Limited (Plant \& Food Research), Palmerston North Research Centre, Palmerston North 4442, New Zealand. ${ }^{2}$ UMR 1121 Nancy Université-Institut National de la Recherche Agronomique Agronomie Environnement Nancy-Colmar, 2 Avenue de la Forêt de Haye, 54505 Vandoeuvre-lès-Nancy, France. ${ }^{3}$ Plant \& Food Research, Mount Albert Research Centre, Auckland, New Zealand. ${ }^{4}$ Plant \& Food Research, Central Otago Research Centre, Clyde, New Zealand. ${ }^{5}$ IASMA Research and Innovation Centre, Foundation Edmund Mach, San Michele all'Adige, Trento, Italy. ${ }^{6}$ School of Biological Sciences, University of Auckland, Private Bag 92019, Auckland, New Zealand.

\section{Authors' contributions}

DC and CK analyzed the chemical datasets, constructed genetic maps, performed statistical and QTL analysis, developed markers for candidate genes and wrote the manuscript. JF collected fruit samples in the field. MR, WAL, CA and MS processed the fruit. MP and MT developed and screened SNP markers in the segregating population. CA, RAH and ACA identified candidate genes in the apple genome sequence. TKM and SEG provided expertise on chemical analysis and genetic mapping, respectively. ACA, DC and WAL designed the experiments edited the manuscript and were project co-leaders. All authors read and approved the final manuscript.

Received: 18 July 2011 Accepted: 23 January 2012

Published: 23 January 2012

\section{References}

1. Willett WC: Balancing life-style and genomics research for disease prevention. Science 2002, 296(5568):695-698.

2. McGhie TK, Hunt M, Barnett LE: Cultivar and growing region determine the antioxidant polyphenolic concentration and composition of apples grown in New Zealand. J Agric Food Chem 2005, 53(8):3065-3070.

3. Boyer J, Liu RH: Apple phytochemicals and their health benefits. Nutr J 2004, 3(5), (12 May 2004).

4. Davey MW, Kenis K, Keulemans J: Genetic control of fruit vitamin C contents. Plant Phys 2006, 142(1):343-351.

5. Hertog MGL, Hollman PCH, Katan MB, Kromhout D: Intake of potentially anticarcinogenic flavonoids and their determinants in adults in the Netherlands. Nutr Cancer 1993, 20(1):21-29.

6. Vinson JA, Su XH, Zubik L, Bose P: Phenol antioxidant quantity and quality in foods: Fruits. J Agric Food Chem 2001, 49(11):5315-5321.

7. Arts ICW, Hollman PCH: Polyphenols and disease risk in epidemiologic studies. Am J Clin Nutr 2005, 81(1):317S-325S.

8. Halliwell B, Rafter J, Jenner A: Health promotion by flavonoids, tocopherols, tocotrienols, and other phenols: direct or indirect effects? Antioxidant or not? Am J Clin Nutr 2005, 81(1):268S-276S.

9. Feng RT, Lu YJ, Bowman LL, Qian Y, Castranova V, Ding M: Inhibition of activator protein-1, NF-kappa B, and MAPKs and induction of phase 2 detoxifying enzyme activity by chlorogenic acid. J Bio Chem 2005, 280(30):27888-27895

10. Stevenson DE, Hurst RD: Polyphenolic phytochemicals - just antioxidants or much more? Cell Molec Life Sci 2007, 64(22):2900-2916.

11. Manach C, Williamson G, Morand C, Scalbert A, Remesy C: Bioavailability and bioefficacy of polyphenols in humans. I. Review of 97 bioavailability studies. Am J Clin Nutr 2005, 81(1):230S-242S.

12. Recent advances in polyphenol research. Edited by: Daayf $F$, Lattanzio $V$ 2008, 1.

13. Recent advances in polyphenol research. Edited by: Santos-Buelga C, Escribano-Bailon MT, Lattanzio V 2010, 2.

14. Volz RK, McGhie TK: Genetic variability in apple fruit polyphenol composition in Malus $\times$ domestica and Malus sieversii germplasm grown in New Zealand. J Agric Food Chem 2011, 59(21):11509-11521.

15. Mattila $P$, Hellström J, Törrönen R: Phenolic acids in berries, fruits, and beverages. J Agric Food Chem 2006, 54(19):7193-7199.

16. Laurens F: Review of the current apple breeding programmes in the world: objectives for scion cultivar improvement. Acta Hort 1999, 484:163-170.

17. Chagné D, Carlisle CM, Blond C, Volz RK, Whitworth CJ, Oraguzie NC, Crowhurst RN, Allan AC, Espley RV, Hellens RP, et al: Mapping a candidate gene (MdMYB10) for red flesh and foliage colour in apple. BMC Genomics 2007, 8:212.

18. Espley RV, Brendolise C, Chagne D, Kutty-Amma S, Green S, Volz R, Putterill J, Schouten HJ, Gardiner SE, Hellens RP, et al: Multiple repeats of a promoter segment causes transcription factor autoregulation in red apples. Plant Cell 2009, 21(1):168-183.

19. Espley RV, Hellens RP, Putterill J, Stevenson DE, Kutty-Amma S, Allan AC: Red colouration in apple fruit is due to the activity of the MYB transcription factor, MdMYB10. Plant J 2007, 49(3):414-427.

20. Velasco R, Zharkikh A, Affourtit J, Dhingra A, Cestaro A, Kalyanaraman A, Fontana P, Bhatnagar SK, Troggio M, Pruss D, et al: The genome of the domesticated apple (Malus x domestica Borkh.). Nat Genet 2010, 42(10):833-839.

21. Sonnante G, D'Amore $R$, Blanco E, Pierri CL, De Palma M, Luo J, Tucci M, Martin C: Novel hydroxycinnamoyl-coenzyme A quinate transferase genes from artichoke are involved in the synthesis of chlorogenic acid. Plant Phys 2010, 153(3):1224-1238. 
22. Takos AM, Ubi BE, Robinson SP, Walker AR: Condensed tannin biosynthesis genes are regulated separately from other flavonoid biosynthesis genes in apple fruit skin. Plant Sci 2006, 170(3):487-499.

23. Takos AM, Jaffe FW, Jacob SR, Bogs J, Robinson SP, Walker AR: Lightinduced expression of a MYB gene regulates anthocyanin biosynthesis in red apples. Plant Phys 2006, 142(3):1216-1232.

24. Cheng FS, Weeden NF, Brown SK: Identification of co dominant RAPD markers tightly linked to fruit skin color in apple. Theor Appl Genet 1996, 93(1-2):222-227.

25. Maliepaard C, Alston FH, van Arkel G, Brown LM, Chevreau E, Dunemann F, Evans KM, Gardiner S, Guilford P, van Heusden AW, et al: Aligning male and female linkage maps of apple (Malus pumila Mill.) using multi-allelic markers. Theor Appl Genet 1998, 97(1-2):60-73.

26. Lepelley M, Cheminade G, Tremillon N, Simkin A, Caillet V, McCarthy J: Chlorogenic acid synthesis in coffee: An analysis of CGA content and real-time RT-PCR expression of $H C T, H Q T, C 3 H 1$, and CCOAOMT1 genes during grain development in C. canephora. Plant SCi 2007, 172(5):978-996.

27. Menin B, Comino C, Moglia A, Dolzhenko Y, Portis E, Lanteri S: Identification and mapping of genes related to caffeoylquinic acid synthesis in Cynara cardunculus L. Plant Sci 2010, 179(4):338-347.

28. Szankowski I, Flachowsky H, Li H, Halbwirth H, Treutter D, Regos I, Hanke M$V$, Stich K, Fischer T: Shift in polyphenol profile and sublethal phenotype caused by silencing of anthocyanidin synthase in apple (Malus sp.). Planta 2009, 229(3):681-692.

29. Conner PJ, Brown SK, Weeden NF: Randomly amplified polymorphic DNAbased genetic linkage maps of three apple cultivars. J Am Soc Hort Sci 1997, 122(3):350-359.

30. Harker FR, Kupferman EM, Marin AB, Gunson FA, Triggs CM: Eating quality standards for apples based on consumer preferences. Postharv Bio Tech 2008, 50(1):70-78.

31. Hosono S, Faruqi AF, Dean FB, Du YF, Sun ZY, Wu XH, Du J, Kingsmore SF, Egholm M, Lasken RS: Unbiased whole-genome amplification directly from clinical samples. Genome Res 2003, 13(5):954-964.

32. Tobler AR, Short S, Andersen MR, Paner TM, Briggs JC, Lambert SM, Wu PP, Wang Y, Spoonde AY, Koehler RT, et al: The SNPlex genotyping system: a flexible and scalable platform for SNP genotyping. J Biomol Tech 2005, 16(4):398-406.

33. Grattapaglia D, Sederoff R: Genetic linkage maps of Eucalyptus grandis and Eucalyptus urophylla using a pseudo-testcross: Mapping strategy and RAPD markers. Genetics 1994, 137(4):1121-1137.

34. Van Ooijen JW, Voorrips RE: JoinMap ${ }^{\oplus}$ 3.0, Software for the calculation of genetic linkage maps. Wageningen, The Netherlands: Plant Research International; 2001

35. Ooijen V: MapQTL5, Software for the mapping of quantitative trait loci in experimental populations. Wageningen, Netherlands; 2004.

36. Chagné D, Gasic K, Crowhurst RN, Han Y, Bassett HC, Bowatte DR, Lawrence TJ, Rikkerink EHA, Gardiner SE, Korban SS: Development of a set of SNP markers present in expressed genes of the apple. Genomics 2008, 92(5):353-358.

37. Crowhurst RN, Davy M, Deng C: BioView - an enterprise bioinformatics system for automated analysis and annotation of non-genomic DNA sequence. In 3rd International Rosaceae Genomics Conference. Edited by: Gardiner SE. Napier, New Zealand; 2006:

doi:10.1186/1471-2229-12-12

Cite this article as: Chagné et al:: QTL and candidate gene mapping for polyphenolic composition in apple fruit. BMC Plant Biology 2012 12:12.

\section{Submit your next manuscript to BioMed Central and take full advantage of:}

- Convenient online submission

- Thorough peer review

- No space constraints or color figure charges

- Immediate publication on acceptance

- Inclusion in PubMed, CAS, Scopus and Google Scholar

- Research which is freely available for redistribution

Submit your manuscript at www.biomedcentral.com/submit
Biomed Central 